\title{
Documentos e indocumentados: Antropología urbana, inmigración y ciudadanía
}

\author{
Documents and the Undocumented: \\ Urban Anthropology, immigration, and citizenship
}

\author{
Juan Thomas ORDÓÑEZ \\ Escuela de Ciencias Humanas \\ Universidad del Rosario-Bogotá (Colombia) \\ juan.ordonez@urosario.edu.co
}

Recibido: 10 de mayo de 2012

Aceptado: 15 de noviembre de 2012

\section{Resumen}

Este artículo explora la cotidianidad de jornaleros inmigrantes "indocumentados" en el Norte de California a partir de las prácticas de documentación formales e informales que marcan su vida. A través del uso de documentos de identidad emitidos por ONGs y otras instituciones, los inmigrantes en estas páginas logran vivir y trabajar sin reconocimiento oficial. Metodológicamente, sin embargo, es difícil entender cómo funcionan estas dinámicas porque están basadas en referentes inciertos y cambiantes; no hay, en otras palabras, reglas claras que determinen los usos y efectos de ciertos documentos. Así, sugiero que entender las formas de lidiar con la documentación o su ausencia debe acoplarse a las realidades de las poblaciones urbanas dispersas, donde el conocimiento del mundo social circundante es incompleto y está regido por la desinformación y el rumor.

Palabras clave: Migraciones, indocumentados, ciudadanía, Latinoamérica, Estados Unidos.

\begin{abstract}
This article explores the everyday life of "undocumented" immigrants working as day laborers on the streets of Northern California by looking at the formal and informal practices of documentation that shape their lives. Through the use of IDs issued by NGOs and other institutions, the immigrants in these pages live and work without formal recognition. Methodologically it is difficult to understand how the dynamics of documentation function because they are based on unstable and ever-changing referents; there are, in other words, no clear rules that determine the use and effects that some documents have. I thus suggest that understanding the documentation practices of a dispersed population living in a vast urban area entails an approach that fits their confusing realities where knowledge of the social world around them is incomplete and ruled by rumor and hearsay.
\end{abstract}

Keywords: Migration, undocumented immigrants, citizenship, Latin America, United Sates.

Referencia normalizada: Ordóñez, J.T. (2013) Documentos e indocumentados: Antropología urbana, inmigración y ciudadanía, en Revista de Antropología Social, 22: 83-101. 
SUMARIO: 1 . Introducción 2. La documentación informal y la ciudadanía contemporánea 3. Ciudadanías paralelas 4. Reflexiones sobre la etnografía de la ciudadanía paralela 5. Referencias Bibliográficas.

\section{Introducción}

Este artículo aborda la cotidianidad de inmigrantes irregulares en el área de la Bahía de San Francisco, California — Estados Unidos_- desde las prácticas de documentación informal que hacen posible su vida diaria. Busco hacer una reflexión sobre el quehacer antropológico en entornos urbanos donde tanto los sujetos de estudio como el investigador comparten espacios sociales complejos en que ninguno tiene conocimiento preciso de todos los aspectos que rigen su vida. Sugiero que hacer investigación etnográfica en este contexto demanda de la antropología una consciencia explícita del entendimiento fraccionado y mal informado de las prácticas que constituyen la ciudadanía moderna a partir de un hecho contradictorio: en la medida que uno empieza a acercarse al día a día de los inmigrantes "indocumentados" en Estados Unidos, se hace evidente que su existencia está marcada por el uso de documentos, tanto oficiales - en el sentido de que son expedidos por un gobierno particular - como extraoficiales o informales. Esto ilustra la miopía que puede causar la simple palabra "indocumentado" de cara a las realidades que esconden las categorías políticas y sociales que usamos para describir diferentes poblaciones ${ }^{1}$. En un lugar familiar al investigador, donde su cotidianidad está inscrita tanto espacialmente como conceptualmente en el mundo social de la gente que estudia, es fácil perder de vista que algo tan básico como los documentos de identidad no sólo pueden tener significados diferentes para distintas personas, sino que los usos que se les dan difieren significativamente de su propósito original.

Mi trabajo de campo empezó en el área de la Bahía de San Francisco, con hombres y mujeres centroamericanos que, a través de una ONG, solicitaban asilo político después de entrar en los Estados Unidos como inmigrantes irregulares. La mayoría de las personas que conocí no tenía conocimiento antes de migrar sobre el asilo político y sus implicaciones migratorias, lo que significa que "descubrieron," una vez dentro del país, que era posible conseguir "papeles" a través de la solicitud. Tras dos años de ser intérprete (español/inglés) en las entrevistas de asilo, decidí seguir a algunos de los hombres que conocí a las calles dónde se paraban a esperar trabajos temporales como jardineros, pintores, y "toderos" en mudanzas y obras. Pasé dos años sentado en un muro de la parada o esquina de Berkeley ${ }^{2}$

${ }^{1}$ En este artículo trato de evitar el término de inmigrante "ilegal", aunque abordo la legalidad y la legitimidad más adelante. Uso los términos "indocumentado" e "irregular" para referirme a personas que han cruzado las fronteras nacionales sin pasar por los servicios de inmigración. Como se hará evidente en este artículo, estos términos también presentan problemas conceptuales.

${ }^{2}$ El área de la Bahía es un conglomerado de ciudades y pueblos que básicamente rodean la Bahía de San Francisco y que constituyen un espacio urbano casi continuo. Mi trabajo se realizó primariamente en Berkeley que queda entre Oakland y San Francisco, las dos ciudades principales de la región. 
— los términos son guatemaltecos y mexicanos respectivamente- acompañando a varios hombres mientras esperaban trabajo durante la peor crisis económica que ha visto el país en las últimas décadas. Estudié la vida diaria de aproximadamente veinte hombres entre los 20 y los 55 años que habían migrado irregularmente sin sus familias desde México, Guatemala, El Salvador y, en menor grado, Honduras. En total estuve más de dos años (2007-2009) haciendo investigación etnográfica entre jornaleros latinoamericanos en el área urbana dónde viví durante seis años mientras realizaba estudios de doctorado.

Los documentos juegan un papel implícito en mi trayectoria de investigación. Aunque originalmente mis objetivos eran entender el asilo político como una forma de legalizar el estatus migratorio, o en palabras de los inmigrantes mismos, de arreglar papeles, no era en este campo de acción que los documentos estaban teniendo un impacto claro sobre las personas que estudiaba. Muchos entendían el asilo como una ayuda que se ofrecía a personas pobres que habían tenido vidas difíciles y violentas, pero veían la conclusión concreta del proceso como la obtención del permiso [de trabajo]. Cuando les explicaba que el asilo podía conllevar al estatus de residente permanente en tan sólo un año y, si pagaban impuestos, a la ciudadanía norteamericana en cinco años, muchos me miraban confundidos. "¿Residencia? ¿Ciudadanía? ¿Eso es mejor que el permiso?” preguntaban. Siendo un estudiante de doctorado con dos nacionalidades, casado con una colombiana con quien tuve que pasar un infierno de trámites para obtener su residencia, me era inconcebible que la gente no tuviera claro las implicaciones de estos diferentes estatus migratorios. Atribuí esta confusión no sólo al nivel de educación de las personas - muchos de ellos no sabían leer ni escribir y ninguno había viajado internacionalmente de forma regular antes de llegar a los Estados Unidos - sino también a las ambigüedades del sistema de asilo, que demandaba de los aspirantes una familiaridad íntima con la burocracia estadounidense y con las formas de entender la violencia que manejaban los oficiales y el gobierno (Ordonez, 2008).

Sin embargo, esta confusión no era exclusiva de las personas que pedían asilo, y una gran mayoría de los jornaleros mexicanos, salvadoreños y guatemaltecos que conocí en la parada de Berkeley — casi todos con educación primaria y algunos con educación secundaria - tampoco entendían claramente la diferencia entre una "visa" (visado) y un pasaporte, entre la residencia permanente y un permiso de trabajo. Los inmigrantes indocumentados que trabajaban como jornaleros no eran como los muestran en televisión y en otros medios, donde se tiende a presentarlos como personas que vienen a los Estados Unidos con la intención clara de establecerse y conseguir "papeles." Más bien encontré inmigrantes para quienes estos "papeles" significan diferentes cosas y, en general, son algo sin una forma clara. En la mayoría de los casos se entienden como un permiso de trabajo y la seguridad de no ser deportado; opciones que se materializan para algunos a través de procesos igualmente confusos, como el asilo, que los inmigrantes escogen seguir sin entenderlos bien.

Los documentos que hacen posible las diferentes formas de ciudadanía oficial tenían significados extraños, producto de rumores y cuentos que la gente 
intercambiaba en la esquina. Los "papeles" eran, para la mayoría de estos hombres, cosas distantes e inalcanzables cuyos significados se entremezclaban pero cuyos efectos no tenían impacto claro sobre sus vidas diarias. A primera vista, los jornaleros eran realmente "indocumentados" en este sentido, y mi conocimiento como estudiante de la migración hizo posible largas conversaciones donde se me pedía corroborar o desmentir las mitologías asociadas a la obtención del estatus "legal." En cierta forma esto me dio una perspectiva incompleta de lo que implica la ciudadanía para personas cuya legitimidad como actores sociales no es reconocida por el estado. Asumir que su vida era regida por estos "papeles" me hizo perder de vista el hecho de que aunque tenían una importancia simbólica, el diario vivir realmente se constituía a través de otros documentos, menos problemáticos legalmente, pero cuyos significados eran también ambiguos. Fue así que encontré prácticas confusas en el uso de los documentos de los países de origen y otras formas de identificación expedidas por ONGs y otras organizaciones. Tales usos son los que hacen posible que los inmigrantes indocumentados lleven una vida aparentemente normal, donde se comportan como "ciudadanos" de los espacios que habitan, pero que al mismo tiempo contribuyen a la precariedad de su existencia social en un país que aprovecha su trabajo sin velar por sus derechos y necesidades.

Hay una gran diferencia entre trabajar con personas íntimamente involucradas en un proceso oficial migratorio como lo es, al fin y al cabo, la aplicación para asilo político, y trabajar con jornaleros indocumentados en la calle. Mientras que en el primer caso, las condiciones de campo y las preocupaciones de todos los involucrados - los buscadores de asilo, sus abogados, las ONGs y el antropólogo/ intérprete - giran en torno a los "papeles" que se buscan obtener en una situación anómala y estresante ${ }^{3}$, el segundo implica pasar horas hablando en una situación que se repite a diario. Aunque algunos de los jornaleros eran, a su vez, buscadores de asilo, en la calle las conversaciones no trataban, como lo había esperado antes de llegar la primera vez, explícitamente de asuntos migratorios.

En un ambiente supuestamente hostil a los inmigrantes - eran los últimos meses del gobierno de G.W. Bush (2007-2008) y la inmigración "irregular" estaba sobre la mesa en ambas plataformas políticas - , las conversaciones en la calle trataban principalmente temas como el costo de la comida, pagar la renta y los servicios, la atención médica y el distanciamiento afectivo entre estos hombres y sus familias en los países de origen (Ordonez, 2012). Aun cuando los jornaleros se preocupaban por la situación política y migratoria, lo que se discutía comúnmente para pasar el tiempo estaba más relacionado con las contingencias del trabajo y de la vida diaria. El cómo conseguir una cita médica, un teléfono celular, pagar las cuentas, contactar

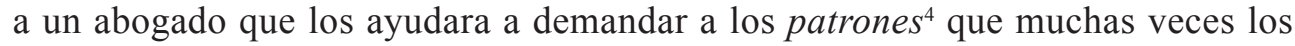
contrataban para hacer trabajos peligrosos y duros que después no pagaban; éstos eran los temas que estaban en la agenda de casi todos los hombres. A medida que

${ }^{3}$ El proceso de buscar asilo crea una situación extrema en la que el sujeto se ve vigilado por un gobierno que en otras instancias no está presente en su vida (ver Coutin, 2005; Ordonez, 2008)

${ }^{4}$ Uso el término "patrón" porque es el que se usaba en las esquinas donde trabajé. 
fui conociendo a algunos jornaleros a fondo, mi manejo del inglés y mi acceso a las páginas informativas en Internet me convirtieron en una fuente de información. Inevitablemente, terminé ayudando a varios hombres en algunas de estas situaciones. Y fue en ese momento cuando lo que entendía del método etnográfico empezó a cambiar. Mas que participar en las actividades de los jornaleros, de hablar con ellos y diseñar entrevistas en profundidad, terminé fijándome en el uso de los innumerables papelitos plastificados que cargaban, y estudiando los efectos que tenían éstos sobre su existencia y las teorías que sobre ellos rondaban en la parada.

Empecé entonces a tomar nota de los diferentes tipos de identificación que cargaban mis informantes en sus billeteras. Aproveché además una práctica común entre desconocidos con la que aliviábamos las tediosas horas de espera en el frío de las mañanas; esto es, el acto de sacar la billetera para mostrarnos las fotos que inevitablemente implican una identificación, burlándonos los unos de los otros por las modas de años pasados o por la cara de "degenerado" que aparecían en los diversos documentos dentro de la multiplicidad de papeles que cada uno cargaba. $\mathrm{Me}$ di cuenta que los jornaleros no sólo tenían los "papeles" pertinentes a un hombre adulto de sus respectivos países - una identificación estatal, licencia de conducción y en algunos casos un registro de servicio militar- sino que también cargaban documentos emitidos por ONGs que proveían servicios de salud y asistencia legal, licencias de conducción californianas vencidas ${ }^{5}$, tarjetas de los seguros de sus vehículos y documentos de identidad falsos. Todos estos documentos eran usados para identificar a su dueño en diferentes situaciones, desde sus interacciones con los servicios de salud, en las cortes menores para demandar a sus patrones, para solicitar trabajos, comprar teléfonos celulares, firmar contratos de vivienda, lidiar con la policía y pagar los servicios de electricidad, gas, teléfono y, en algunos casos aislados, Internet y televisión por cable. En otras palabras, era a través de estos documentos que los jornaleros podían moverse, trabajar, y vivir en general como miembros de su mundo social —es decir ciudadanos de alguna índole-.

\section{La documentación informal y la ciudadanía contemporánea}

La ciudadanía moderna ha estado intrínsecamente atada a la nacionalidad desde el siglo XVIII. Esta asociación ha producido formas de ciudadanía que, según el contexto, incluyen diferencialmente a una parte de la población de cada país, al mismo tiempo que excluyen, por diferentes razones, a algunos grupos sociales como las mujeres, las minorías étnicas, los inmigrantes y otros (Agamben, 1998; Arendt, 1979; Sassen, 2006). En efecto, este movimiento histórico, es decir la asociación entre ciudadanía y territorio, parte del proyecto de Estado-Nación que buscó desarticular las asociaciones políticas y culturales que hasta entonces habían primado en la historia; esto es, la pertenencia política a las ciudades y regiones, antiguos principados y ciudades estado (Holston y Appadurai, 1999; Sahlins, 1989). De esta

${ }^{5}$ Estos eran los pocos hombres que llevaban más de 5 años ahí y por ende habían tenido la oportunidad de obtener una licencia cuando era permitido. También había algunos que habiendo vivido esta época habían regresado a sus países y ahora se encontraban en un segundo o tercer viaje. 
forma, todos asociamos la ciudadanía con una pertenencia legal, cultural, social e ideológica a un territorio definido por el poder político, administrativo y de significación que sobre él tiene el estado. La ciudadanía se constituye como un conglomerado de derechos y deberes que define a los sujetos que se encuentran dentro de él (Ong, 2003). Los inmigrantes caen dentro de estas definiciones como residentes o visitantes que han recibido el aval y la protección del estado receptor o que, por el contrario, han cruzado sus fronteras sin permiso y por ende no gozan de una configuración jurídica que legitime su presencia.

Sin embargo, como han mencionado varios autores, la relación entre territorio, estado y ciudadanía, actualmente, no es tan estable (Appadurai, 1996; Holston y Appadurai, 1999; Ong, 1999; Sassen, 2006). La globalización, sin importar cómo la definamos, ha resultado en procesos complejos donde las grandes ciudades han vuelto a emerger como lugares centrales a la constitución de la ciudadanía y donde la articulación de los derechos y deberes de sus residentes se sale del marco del Estado-Nación. En efecto, muchas de las grandes ciudades del mundo tienen relaciones propias y particulares con los procesos y flujos transnacionales; relaciones que no siempre reflejan las políticas oficiales del estado al que pertenecen (Sassen, 2008). Este es el caso del área de la Bahía de San Francisco, un conglomerado de ciudades y pueblos en el norte de California considerado como una de las regiones más liberales y tolerantes de los Estados Unidos.

Al igual que muchas de las grandes ciudades del país, San Francisco, Oakland, Berkeley y otras, han instaurado políticas de ayuda y apoyo a los inmigrantes sin importar su estatus migratorio. Conocidas como políticas de Santuario ${ }^{6}$, estas prácticas oficiales generalmente implican programas de acceso a servicios legales y de salud, la no cooperación entre la policía local y los servicios migratorios, y otros programas cuyo objetivo es reconocer la contribución de los inmigrantes a la vida social y económica de la región y promover una responsabilidad social frente a su situación. Sobra decir que estas políticas reflejan las actitudes generales de la población de estas ciudades, pero que dependiendo del clima socio-económico entran a jugar importantes papeles en las discusiones políticas. En general, en los Estados Unidos, al igual que en otros países industrializados, hay una tendencia a culpar a las "hordas" de inmigrantes indocumentados de muchos de los problemas sociales, culturales y laborales en momentos de declive económico (Chavez, 2001; Inda, 2006; Ngai, 2004).

En términos del problema de la ciudadanía moderna, estas ciudades Santuario son un ejemplo claro de las inconsistencias entre el Estado-Nación, la nacionalidad, y el acceso a derechos y servicios, que entendemos por ciudadanía. Promueven elementos de lo que Holston y Appadurai (1999: 4) resaltan como la dicotomía entre aspectos de ciudadanía formal y de ciudadanía sustantiva, siendo la primera "la

${ }^{6}$ El origen de estas políticas está en la década de los años 80 del siglo pasado cuando algunas ONGs y organizaciones religiosas empezaron el "Movimiento de Santuario" cuyo fin era proteger a los refugiados de guerras en Centroamérica - financiadas directa e indirectamente por el gobierno estadounidense - y que por sus particularidades políticas dejaba desprotegidos y abiertos a la deportación a miles de personas (Coutin, 1993; Coutin, 2000; Loescher, 1993). 
pertenencia al estado-nación" y la segunda "el rango de derechos civiles, políticos, culturales y socioeconómicos que la gente tiene y ejerce". Si bien en una perspectiva tradicional la ciudadanía sustantiva es una función de la ciudadanía formal, en la práctica, lo sustantivo puede llegar a ser independiente de una pertenencia formal al Estado-Nación. De esta forma, en la ciudades Santuario los inmigrantes encuentran una mayor tolerancia a su presencia, lo cual se traduce en el acceso a servicios básicos de salud y protección social y, más importante aún, a la no colaboración entre la policía y los servicios migratorios - $\mathrm{ICE}^{8}$ por sus siglas en inglés, más conocida por los inmigrantes en cuestión como la migra - Este importante punto, que no todos los inmigrantes entienden, significa que pueden acceder a la protección de la policía - poner denuncias, pedir ayuda, etc.pregunten por su estatus migratorio o los reporten a la migra ${ }^{9}$.

\section{Ciudadanías paralelas}

Autores como Holston y Appadurai (1999) (ver también Holston, 2008, Sassen, 2006 y Ong, 2003; 2006) subrayan las relaciones entre los migrantes y otras comunidades marginales con la ciudad, de tal forma que se hace evidente que la ciudadanía contemporánea se constituye como mucho más que la pertenencia a un territorio nacional bajo la protección y el reconocimiento del estado. Las prácticas de ciudadanía substantivas ofrecen entonces aspectos que legitiman, en cierta medida, a diferentes comunidades excluidas (Holston, 1999). Entre estas prácticas se pueden encontrar el acceso a servicios legales y de salud, la protección de entidades policiales, la educación, el trabajo, y otras. También considero la habilidad de moverse libremente y el acceso a contratos de arrendamiento - sean éstos formales o no-, servicios públicos y hasta teléfonos celulares, como efectos de estas prácticas. Sin embargo, en el caso de los jornaleros latinoamericanos de Berkeley, tal legitimidad tiende a ser inestable e incierta porque queda abierta a la desarticulación de las instancias que produce, a través de políticas explícitas e implícitas que tienen como efecto limitar la inclusión real y legal de dichas poblaciones.

Para los inmigrantes indocumentados que estudié, la cotidianidad se constituye a través de prácticas sociales y legales que establecen una forma de ciudadanía que en muchos aspectos hace su vida aparentemente "normal" y legítima. La naturaleza de la ciudadanía que producen es incierta y pocas veces conlleva a una legitimación oficial por parte del estado. Esta ciudadanía es paralela a la ciudadanía formal, la imita y sigue una racionalidad similar, pero nunca la intersecta. La ciudadanía paralela tiene dos funciones primarias que aparentemente contradicen cualquier noción que se pueda elaborar sobre el asunto. Hace de los inmigrantes sujetos legibles que pueden ser incorporados al cuerpo de la nación estadísticamente, de forma tributaria y económica (ver Inda, 2006; Ngai, 2004), y les ofrece acceso a algunos servicios básicos, pero al mismo tiempo garantiza su marginalización y promueve su

${ }^{7}$ Todas las traducciones de las citas en inglés son mías.

${ }^{8}$ United States Immigration and Customs Enforcement.

${ }^{9}$ Sin embargo, la policía debe informar al ICE si en el sistema hay una orden de arresto en nombre de la persona que ellos tienen en custodia. 
estigmatización en ambientes políticos donde los inmigrantes entran a jugar el papel de chivo expiatorio de los males que acechan a la nación. La ciudadanía paralela es, en efecto, una configuración contradictoria y cambiante que depende del ambiente político, social y económico del momento, algo que apunta a la advertencia de De Genova (2002) sobre cómo no se puede entender "la migración" como algo general, sino que debe ser tomada como una construcción social atada a contextos específicos.

En mi trabajo de campo fue algo sutil y de poca importancia lo que me hizo empezar a buscar un acercamiento a la puesta en práctica de los aspectos de lo que he llamado la ciudadanía paralela. Empecé a entender el asunto a través de los documentos que los jornaleros cargaban en sus billeteras, y sólo después de varios meses de observar sin reflexionar el común suceso de sacarlos para mostrárselos a los compañeros y hacer énfasis en algo que se estaba discutiendo. Este énfasis tenía usualmente uno de dos objetivos; el probar que algún contacto institucional o comercial era posible con ellos - como por ejemplo mostrar con qué documento dejaron a una persona comprar un teléfono celular-o, como ya dije, en los intercambios burlones de información sobre nuestros pasados, donde las fotos de los documentos jugaban un papel importante.

De esta forma, mi análisis se basa en las interacciones cotidianas donde el uso de documentos específicos se discute. Parto entonces de un fragmento de mis notas de campo tomadas aproximadamente cinco meses después de haber llegado a la parada:

Lorenzo, Hernando, Beto, Jorge y yo estábamos hablando de las diferentes formas de sacar los papeles, de las nuevas dificultades y la lejana posibilidad de otra amnistía ${ }^{10}$. Les digo que igual si hacen una amnistía como la anterior les va a tocar pagar todos los impuestos de los años que llevan acá. Hernando sube los hombros rápidamente: "Igual yo he pagado siempre que trabajo en una compañía, siempre meto el social". "Sí, pero quién sabe como funcione si es uno chueco ${ }^{11 "}$, le digo. Ninguno sabe bien. Lorenzo pregunta si será verdad que Bush va a mandarnos a todos dinero y dice que la última vez le llegó a él también: "Van a ser como seiscientos [dólares] ¿no?"

Jorge, siempre sonriendo, empieza a hablar emocionadamente. Dice que ayer llegó la migra a Oakland y se llevó a 50 trabajadores. No le creemos porque traigo el periódico y no encontramos nada. Dice que a un amigo se lo llevaron otra vez porque llegaron a su casa y abrió la puerta. Es un error, coincidimos todos. Siempre hay que preguntar si traen una orden. Hernando vuelve a hablar de la vez que los pararon y esposaron en el piso porque los confundieron con otros: "eso no cuenta porque nos soltaron ¿verdad?" Yo le digo que si. Lorenzo dice que a veces lo engañan a uno, que dicen ser la policía pero son la migra. Jorge habla de otro compa

${ }^{10}$ La amnistía se refiere a un programa de regularización de inmigrantes indocumentados en los años 80, el Immigration Reform and Control Act de 1986 (Ngai, 2004; Stephen, 2007). Ninguno de los jornaleros en la parada se había beneficiado de esto, pues la mayoría eran inmigrantes recientes.

${ }^{11}$ Falso. 
que mostró el social chueco allá en Oakland y lo arrestaron. Con Lorenzo nos miramos. No hay porqué mostrar eso, "solo con la tarjeta consular o cualquier ID", dice Lorenzo sacando de la billetera dos identificaciones, una de un centro que ayuda a los inmigrantes en Fruitvale ${ }^{12}$ y, la otra, su identificación de la escuela de adultos de Berkeley. Jorge saca una identificación que lleva el logo de la empresa de transporte público. Tiene una calcomanía de este mes y su nombre completo ${ }^{13}$. "¿Y eso de dónde lo sacó?" le pregunto. Él sonríe mientras Lorenzo contesta: "Eso se lo dieron porque está enfermo, porque está mal de la cabeza." Lorenzo se toca la sien con el índice para hacer énfasis. Jorge sonríe y dice "eso" apuntándole al otro hombre. Me parece un poco duro como habla Lorenzo y pido que me expliquen. Jorge no dice nada, sonríe y apunta a Lorenzo que sigue tratando de contestar y repite, eso si, amablemente, que el hombre está mal de la cabeza. "Vos estás mal de la cabeza, por eso te lo dan ¿Vah?" le dice Lorenzo y Jorge repite nuevamente "éste si sabe, lo sabe..."

Los hombres en esta nota tienen diferentes edades y trayectorias de vida. Lorenzo, el más viejo, tiene aproximadamente 55 años y lleva 12 en Estados Unidos. Hernando, el más joven, tiene aproximadamente 20 y lleva tres o cuatro años en la región. Ambos tienen tarjetas de seguridad social chuecas, compradas en el mercado negro de Oakland o San Francisco por 80 dólares, más o menos — precios del 2007- Estas tarjetas son usadas cuando consiguen trabajo en "compañías;" es decir, empresas que los declaran como empleados ante el estado. Con los números de seguridad social falsos, los jornaleros, a su vez, declaran y pagan los impuestos como si fueran ciudadanos o residentes con permiso de trabajo. El sistema funciona igual que con un número de seguridad social bueno y en muchas ocasiones reciben una devolución anual después de hacer su declaración de impuestos. En el caso de Lorenzo, aparentemente también recibió una devolución extraordinaria que hizo el gobierno para reactivar la economía. El social chueco es un aspecto esencial del trabajo manual explotador en Estados Unidos y en mejores épocas los empleadores les explicaban a los inmigrantes indocumentados despistados dónde conseguirlo ${ }^{14}$. Como ya he mencionado, sin embargo, los dos años que estuve en la parada fueron drásticos económicamente para Estados Unidos y especialmente para los pobres del

${ }^{12}$ Fruitvale es un barrio o sector de la ciudad de Oakland donde se concentra una gran cantidad de la población indocumentada y pobre de la región. Los inmigrantes latinoamericanos tal vez constituyan la mayor cantidad de estos, pero también son notorios los inmigrantes asiáticos y del este de Europa. El sector es lo que en el vernáculo local se considera un "Ghetto Urbano", habitado también por una población afroamericana significativa.

${ }^{13}$ Este hombre guatemalteco debía tener residencia legal o asilo porque recibía dinero del estado por haber sufrido un accidente. Sin embargo, vivía de un "hogar" para indigentes a otro y durante el tiempo que estuvo en Berkeley nunca obtuvo un trabajo regular aunque tenía un trabajador social que lo había inscrito en una base de datos de trabajadores.

${ }^{14}$ En el caso de la gente que obtiene asilo, uno de los problemas cuando les legalizan el estatus migratorio es usar el social bueno; es decir el legítimo número de seguridad social. Muchos de los empleos que tienen estos inmigrantes son trabajos donde los explotan y los empleadores se rehúsan a cambiar el número o los despiden cuando hacen la petición. Para muchos no es clara la diferencia entre el social bueno y el chueco, porque al fin y al cabo se usan para exactamente lo mismo (ver Ordonez, 2008). 
país, entre los cuales están los inmigrantes que estudié. Esto, junto con un incremento en las políticas anti migratorias del estado, hizo cada vez menos probable que los jornaleros consiguieran trabajo regular en empresas donde debían mostrar el social chueco. A pesar de esto, casi todos los hombres tenían uno, y los trabajos donde había que ocuparlos eran los más deseados.

El social chueco es uno de los documentos más problemáticos que poseen estos hombres. En primer lugar, sólo sirve para pagar impuestos y conseguir estos trabajos porque no tiene una foto. En segundo lugar, aunque necesario para trabajar y común entre los inmigrantes indocumentados, constituye un delito poseerlo y usarlo. Es por esto que en la nota anterior Lorenzo aclara que "eso no se muestra" cuando lo detiene a uno la policía o la migra. Los documentos que sí se muestran son como los que sacó él esa mañana. Documentos como las tarjetas para los servicios de salud gratis que ofrecen algunas ONGs en la región o las tarjetas de la escuela de adultos — donde algunos toman clase de inglés gratis-, que se obtienen sólo con los recibos de los servicios del condado - o algo que tenga el nombre de la persona y su dirección- y una identificación con foto - que en muchos casos es la anteriormente mencionada identificación de la $\mathrm{ONG}$ - Algunos jornaleros mexicanos y guatemaltecos también tienen una tarjeta consular que emiten los consulados y consisten en un registro oficial de los ciudadanos de esos países sin importar su estatus migratorio. Sin embargo, mientras que todos los hombres de la esquina entran en contacto con ONGs diariamente, muchos de ellos no saben dónde queda el consulado de su país, ni creen tener suficiente documentación para obtener la tarjeta consular que, al fin y al cabo, no siempre tiene un fin claro para estos inmigrantes. Priman, entonces las identificaciones emitidas por ONGs con direcciones locales a las que se pueden remitir comparecencias, citaciones, y cuentas de cobro.

Los documentos de este tipo son esenciales para la vida en el área de la Bahía. Las más comunes eran las de las clínicas de salud, pero en algunos casos había identificaciones de ONGs que ofrecían ayuda legal a inmigrantes, y en otras tenían identificaciones de fábricas y empresas donde habían trabajado. Los documentos de las ONG son generalmente cartoncitos plastificados con la foto y nombre del jornalero y una dirección local. Esta dirección es a veces la del jornalero pero más comúnmente es la dirección de la entidad que emite la identificación o una dirección local falsa - las ONGs no revisan la información necesariamente-. La dirección, en cierta forma, es lo más importante, porque les da a los inmigrantes una identificación con la misma información que tienen las licencias de conducción y los documentos de identificación del estado de California ${ }^{15}$. Así, tales documentos sirven para poder comprar celulares prepagados — que son esenciales para un jornalero porque le dan acceso a las redes de trabajo entre compañeros y a los patrones que los contratan-y también se pueden usar para identificarse en las situaciones cuando entran en contacto con el estado. Los dos casos más comunes son cuando los llevan a un hospital del condado — donde deben dar prueba de dónde viven para mandar la cuenta de

${ }^{15}$ La licencia de conducción, entre los estadounidenses, es la forma más común de identificación estatal. 
cobro - o cuando los detiene la policía. La segunda instancia es bastante común, pues los jornaleros pasan largas horas parados en calles transitadas y, en el caso de Berkeley, residenciales, donde los habitantes ponen quejas a la policía por disturbios, por ensuciar y obstruir la vía pública, orinar, y consumir alcohol y drogas. Por otro lado, la policía también aparece en las calles y autopistas donde paran los viejos y destartalados vehículos que muchos jornaleros manejan sin licencia.

En los primeros meses de mi trabajo de campo entrevisté al oficial de policía encargado de la zona urbana donde se encuentra la parada. En la mayoría de los casos, cuando la policía responde a quejas sobre los jornaleros, lo que hacen es pedir identificación y multar a los trasgresores; en esta situación, el documento de identidad con dirección local es esencial. Las tarjetas de identidad de los países de origen también son recibidas pero como no incluyen una dirección en Estados Unidos son preferibles en combinación con una de la región. Así, en una ciudad Santuario donde la policía no se comunica con la migra, el documento emitido por la ONG se vuelve el principal documento de identidad, aceptado y recibido en múltiples ocasiones y situaciones. Estas formas de identificación informal terminan reproduciendo la imagen del documento "oficial", imitándolo no sólo en forma — son plastificadas y tienen símbolos y foto- sino en contenido. Tal es su utilidad que algunos jornaleros pagan hasta más de 50 dólares — casi el valor de un social chueco- por documentos emitidos por instituciones que, a partir de un certificado de nacimiento, producen un documento muy parecido a la licencia de conducción de California con una advertencia que dice "esto no es una identificación oficial". En este caso la copia es casi completa, pues los documentos incluyen hologramas y otros semblantes de los documentos oficiales, además de requerir certificados para ser emitidos. De esta forma, el poder mimético de los procesos de documentación informales replica las lógicas de gobierno que el estado articula a través de sus practicas de inscripción, haciendo así manejables los sujetos que se encuentran en sus márgenes (ver Das, 2004).

El problema es que, a diferencia del uso de documentos "oficiales" — aquellos emitidos por una institución del gobierno estadounidense-, los jornaleros no pueden prever la reacción que tendrá la persona a quienes se los muestran. Un caso que presencié varias veces fue con jornaleros que iban a entrevistas de asilo y presentaban su carné de ONG cuando el oficial de asilo les pedía identificación. Al enterarse que no constituía una identificación legítima miraban a sus abogados con gran confusión. Era difícil explicarles que el carné, en muchas ocasiones usado para casarse en el ayuntamiento de Oakland ${ }^{16}$ - que implica un reconocimiento por parte del estado de California-, no era reconocido por el gobierno federal — que otorga el asilo- .

Otra situación donde esta ambigüedad se hace aparente tiene que ver con las licencias de conducción. Muchos de los jornaleros en Berkeley compran carros

${ }^{16}$ Algunos casos de asilo incluyen el esposo o esposa del aspirante, pero la mayoría de los buscadores de asilo no tenían registro de matrimonio porque vivían en unión libre, así que para incluir a su pareja debían casarse ante un juez en el ayuntamiento. 
usados que manejan sin licencia estadounidense. Algunos hombres tienen licencias de sus países de origen, pero muchos manejan sin ningún documento que aluda al uso de un vehículo. Los seguros del vehículo —obligatorios en Estados Unidoslos obtienen a través de aseguradoras que explícitamente ofrecen sus productos a individuos "con o sin licencia". La compra se hace a través de terceros que presentan su licencia y después ponen el nombre del dueño o con las licencias de los países de origen. La práctica es confusa y es bastante seguro que si les piden los papeles del vehículo, la mayoría de los jornaleros no tengan los documentos necesarios para transitar en la calle. Es común, entonces, que estos inmigrantes sean detenidos por la policía — los coches 'de apariencia' hispanos son interceptados a menudo - y que les decomisen los vehículos. Para reclamarlos, las multas son tan altas que es más barato simplemente comprar otro. A primera vista es difícil entender por qué tantos inmigrantes compran estos vehículos, ya que aunque la movilidad es esencial para el trabajo, parece contraproducente tomar el riesgo. Sin embargo, como me explicaron muchas veces, no todos los policías los decomisan y "muchas veces tiene uno buena suerte". En otras palabras, "todo depende", pero de qué depende es realmente un misterio para la mayoría de los jornaleros.

En la nota anterior, Hernando hace referencia a un evento donde fue detenido por la policía y pregunta si eso cuenta, no estando seguro si quedó su nombre registrado en las bases de datos. Hernando no tiene licencia de conducción de ningún país, pero sin embargo ha comprado dos carros - uno fue decomisado dos años antes de la nota- que ha manejado, "sólo con licencia de Dios". A diferencia de muchos de sus compañeros, los policías que lo pararon esa vez estaban buscando unos sospechosos específicos y su objetivo no era simplemente revisar los documentos del vehículo. Hernando y sus acompañantes pasaron unos minutos esposados en el suelo mientras la policía se aseguraba que no eran las personas que buscaban y después los dejaron ir. Esto para él era incomprensible, ya que anteriormente lo habían parado por tener dañada una de las luces y había perdido su automóvil. Así, los jornaleros nunca saben exactamente porqué en algunas ocasiones les quitan el auto y otras no. Varios han perdido uno o dos vehículos y, retenidos por segunda o tercera vez, han mostrado los mismos documentos y recibido sólo una advertencia del oficial o la instrucción de llamar a alguien con licencia para que lo conduzca.

¿Cuándo vale entonces un documento y cuándo no? Esa tal vez sea la pregunta esencial de este trabajo y una que yo mismo no puedo responder porque, como es evidente, depende de instancias sobre las cuales el portador no tiene control ni entendimiento. Muchos atribuyen la buena o mala suerte al estado de ánimo del oficial, su etnicidad, o a la habilidad del jornalero de hacerse pasar por un trabajador humilde y honesto. Pero hay tantos ejemplos a favor y en contra de estas teorías que la suerte es realmente la única que explica todas las instancias. La suerte, en este sentido, constituye realmente una excepción que, por razones desconocidas al inmigrante, se le hace en ciertas ocasiones.

Lo que he llamado "ciudadanía paralela" emerge en estas prácticas de documentación y en los usos que se les da a los documentos que producen. La confusión replica en cierta forma la marginalidad de estas personas porque asegura que cada 
evento sea una excepción y que nunca se esté seguro de lo que pueda pasar cuando se presenten los documentos a las autoridades. Aparece entonces un fetichismo asociado a los documentos que, basado en los rumores que corren por la parada, hace que un tipo de identificación, o hasta una tarjeta de presentación, adquieran el poder de abrir las puertas a un servicio deseado o de eximir al portador de ser detenido o deportado. Por ejemplo, mi amigo Clemente, que tenía "papeles" por asilo político, siempre llevaba la tarjeta de presentación de dos oficiales que lo habían entrevistado cuando fue víctima de un patrón que no le pagó. Para él, esta "prueba" de su familiaridad con la policía podía ayudarlo si lo paraban para multarlo, y nos mostraba las dos tarjetas con orgullo cada vez que alguien se quejaba de un multa. En otro caso, se repartió en la parada una tarjeta roja que tenía en inglés las frases que se le debía decir a la policía o la migra si aparecían en la puerta de la casa. La idea era explicarles a los inmigrantes que sin una orden judicial a nombre de alguien que estaba adentro, los oficiales no podían entrar. Sin embargo, corrió la voz por la calle que existía una "tarjeta roja" que se le podía mostrar a la migra para obligar a los oficiales a soltar a la persona detenida.

Suárez Navaz (1999: 3-5) sugiere que las prácticas de regulación e inscripción jurídica de inmigrantes frente al estado receptor da pie al surgimiento de un "fetichismo de los papeles" ${ }^{\prime 17}$ donde los inmigrantes atribuyen poderes mágicos a los documentos que luchan por conseguir y que representan un proceso de regularización de su estatus como sujetos jurídicos. Los ejemplos anteriores muestran que la magia de los documentos no está limitada a aquellos emitidos por el estado, y que el fetichismo de los papeles - su configuración simbólica como algo cargado de poder social y jurídico - está presente en un sinnúmero de instancias. Al mismo tiempo, por pertenecer a un entorno de instituciones múltiples y de individuos diferentes - en el caso de las tarjetas de presentación-, el poder de los documentos siempre está en entredicho, pues hay tantos ejemplos en pro de su eficacia, como los hay en contra. Unos dicen, por ejemplo, que es mejor no mostrarle a la policía un documento del país de origen, porque si saben el nombre real de la persona la pueden deportar más fácilmente. En consecuencia, cargan carnés de ONG con nombres falsos ${ }^{18}$. Otros prefieren tener ambos carnés con sus nombres verdaderos pero con una dirección falsa. En los dos casos es posible que digan mentiras y escondan los documentos ante la policía, prefiriendo decir que no tienen ningún papel a su nombre. Todo, siempre, depende de la percepción del portador y de lo que haya oído en la calle. Nuevamente, la experiencia del inmigrante no es genérica sino que se

${ }^{17}$ La autora sugiere que este fetichismo no es único a los inmigrantes sino que es también una característica de las configuraciones políticas y sociales de la modernidad en occidente. Como ella, me centro acá en la experiencia de inmigrantes indocumentados tanto por la temática del artículo como por el hecho que su situación marginal hace más evidente, y en cierta forma, más violento, el fenómeno.

${ }^{18} \mathrm{La}$ mayoría de las ONGs, especialmente las que ofrecen servicios de salud, no piden registros de nacimiento o documentos del país de origen porque su objetivo es simplemente tener un registro del individuo en sus bases de datos. No es difícil entonces dar información falsa cuando se sacan estos documentos. 
ata al contexto político, social y económico de un contexto específico (De Genova, 2002). Dependiendo de la cercanía temporal de redadas migratorias — que en el espacio pueden ser tanto cercanas como distantes-, aparecen jornaleros que aseguran conocer gente que fue deportada tras un encuentro aparentemente inconsecuente con la policía o hasta con un abogado al que acudieron. Tales rumores aseguran que el portador esté siempre reticente a buscar ayuda en las instituciones pertinentes; aseguran que el contacto con cualquier entidad que sea o parezca ser "oficial," se evite. Al mismo tiempo, la "ciudadanía paralela" hace posible el día a día en otros espacios como el registrarse para pagar servicios, ir al médico, tomar clases, firmar contratos de arrendamiento y comprar celulares. Los jornaleros se comportan como ciudadanos productivos que trabajan, pagan impuestos — cuando su trabajo es en empresas - , se registran para pagar servicios etc.

El fetichismo de los documentos que he descrito es uno donde el poder de los papeles comprende una diada de inclusión y exclusión que se resuelve a partir de excepciones. Esto hace que la obtención de los papeles oficiales que representarían un "estatus legal" entre en el juego de excepción y se confunda tanto su poder de significado como sus usos en la práctica. No hay diferencia desde la experiencia de los inmigrantes entre una visa y un pasaporte, entre la residencia permanente y el permiso de trabajo. Su poder es incierto, y cada quién tiene sus propias ideas sobre qué documento funciona en qué situación.

\section{Reflexiones sobre la etnografía de la ciudadanía paralela}

Desarrollé el concepto de "ciudadanía paralela" a partir de prácticas observables pero tal vez no aparentes a primera vista en mi trabajo de campo. Responde a una pregunta explícita sobre cómo se constituye la experiencia del migrante a través de la cotidianidad, y es un ejemplo de las contingencias de la etnografía en entornos urbanos donde ni el antropólogo ni sus informantes entienden completamente lo que pasa a su alrededor. Los documentos cumplen acá un papel central, ya que es a través de ellos que las inconsistencias que he descrito se constituyen como un hecho social. Ni yo ni los jornaleros teníamos formas efectivas de determinar cómo funcionan estos documentos porque cada evento establece una excepción que entra a jugar un papel importante en las redes de información y en los rumores que marcan la parada como un centro de información sobre la vida en los Estados Unidos. Así, cuando algunos hombres venían a preguntarme sobre cómo hacer una demanda por impago a un empleador, sacaban sus documentos y pasando uno por uno preguntaban "¿éste sirve? ¿será que con éste?".

Sin importar nuestras trayectorias académicas o nuestras influencias teóricas, los antropólogos tendemos a buscar entornos donde podamos delimitar comunidades, mundos sociales o, en general, algún tipo de estructura que se pueda describir, analizar y explicar. De las tradicionales aldeas y grupos étnicos de la antropología clásica a las vecindades, barrios y subculturas "urbanas" de los años posteriores, y finalmente al estudio de movimientos sociales y ciudadanía moderna, siempre se busca poder definir un grupo que comparta conocimiento y significado del mundo que los rodea. Hacer esto entre inmigrantes indocumentados que trabajan informalmente 
en las esquinas de los Estados Unidos no sólo es imposible, sino que supondría imponer una estructura de orden que está ausente en la calle. La población de la parada es móvil, está constantemente cambiando y, en un complejo urbano inmenso, los jornaleros no viven necesariamente cerca el uno del otro. La competencia entre hombres es grande y los lazos de solidaridad que se pueden establecer son sólo pasajeros. Es difícil, entonces, que se genere un cuerpo de conocimiento específico y corroborado de información que permita a estos hombres acceder a los procesos que he descrito y sus reglas. Además, la mayoría de los jornaleros quiere evitar el contacto con entidades oficiales pero al mismo tiempo sabe que debe estar preparado para hacerlo y no terminar en problemas. No hay pues una "comunidad" de jornaleros, ni tampoco un conocimiento claro de todos los elementos que afectan la vida cotidiana ${ }^{19}$.

En su trabajo sobre el declive y la disolución de las promesas del desarrollo y de la modernidad en Zambia, James Ferguson (1999) se encontró con el hecho de que las condiciones mismas del tema que había escogido estudiar no tenían ninguna de estas características - un orden social claramente comprendido por sus integrantes-. En medio de una crisis económica y social tuvo que acercarse a una población que no "habitaba un orden social bien conocido y estable". Las personas con las que interactuó no tenían un claro conocimiento de qué era los que les estaba ocurriendo, ni entendían el por qué. Esta inestabilidad, para Ferguson, no sólo es la de un mundo en crisis, sino una característica intrínseca de los espacios urbanos donde ningún actor posee un corpus de conocimiento coherente con respecto a un mundo social establecido y dónde tanto el etnógrafo como los "nativos" carecen de un entendimiento claro de lo que les está pasando (1999: 21). Creo que esto se aplica también a la situaciones de miles de inmigrantes "indocumentados" en Estados Unidos y en el resto del mundo. En medio de la marginalización política, social y económica, en un entorno donde el acceso a la información esta mediada por barreras de idioma, educación, y la familiaridad que pueda llegar a tener una persona con el "sistema," es difícil acercarse a los "conocimientos" de ese mundo perteneciendo a una población que vive dispersa en un área urbana gigantesca. Esto plantea un problema difícil de confrontar, pues demanda de la antropología una posición crítica sobre las relaciones en que se inscriben las vidas de quienes estudiamos, ya que "...entender las cosas como lo hacen los nativos [implica] perdernos de gran parte de lo que está pasando" (Ferguson, 1999: 208). Es decir, que acercarnos a la experiencia del "otro" nos obliga a entender el mundo en sus términos, mientras que contextualizarlo para nuestro "mundo" — el académico, la opinión pública, etc. - implica salirnos de su entendimiento. Pero salirnos así significa poner orden en el caos que estamos tratando de conceptualizar.

${ }^{19}$ En efecto, mucho estudios sobre jornaleros tienden a enfatizar la solidaridad entre los hombres que se paran en la esquinas (Malpica, 2002; Pinedo Turnovsky, 2006; Purser, 2009). Sin embargo mi trabajo de campo vio muchas instancias de desintegración de grupos de hombres aparentemente cercanos y pocos lazos de solidaridad fuertes y duraderos, que apunta mas a lo que otros autores han llamado el estado de vulnerabilidad estructural de este tipo de población (Quesada; Hart; Borugois, 2011) 
Como etnógrafo y como persona bilingüe, doctorado y además binacional -e íntimamente familiarizado con dos tipos de burocracia muy diferentes-, tuve que afrontar la aparente inversión de los lugares comunes clásicos de mi profesión, donde el conocimiento del mundo le pertenece a los "nativos" y en el cual debe incursionar el antropólogo para aprender y entender lo que está pasando. En las calles de Berkeley era yo quien entendía mejor el "sistema", era yo quien tenía acceso a las vías de información confiables, y por encima de todo esto, era yo quien estaba más familiarizado con la burocracia estadounidense y, en general, con la burocracia en sí misma. Pero si propusiera "la verdad" del asunto, es decir, si investigara las reglas y razones que hacen posible estas prácticas tan confusas, me arriesgaría a construir unos sujetos perdidos en su propia marginalización. Argumentaría entonces que es falta de información, educación y demás lo que hace que las personas no entiendan los contextos en que estos usos particulares se dan. En cierta forma, buscar una racionalidad al asunto le quita fuerza al hecho de que es su ausencia la que permite el estado de excepción en el que viven millones de inmigrantes indocumentados, muchos de los cuales existen simultáneamente como ciudadanos de facto y como criminales, en tanto que se criminaliza la inmigración irregular (ver Inda, 2006). Mi punto acá es que no hay forma de contextualizar la ciudadanía paralela definitivamente porque su naturaleza misma es inestable, incierta y fugaz. La cotidianidad de los jornaleros en California no está políticamente informada, ni se estructura a partir de un orden social determinado en la parada, sino que es imprevisible y está llena de inconsistencias y confusión.

Mi propuesta es sencilla. Para entender la experiencia de los jornaleros del área de la Bahía fue necesario mirar cómo se mueven e interactúan con su entorno, lo cual situó a los documentos que he descrito como un material imprescindible para el análisis y la explicación antropológica. A partir del uso que los jornaleros hacen de estos "papeles" y de las nociones que sobre ellos manejan, empecé a comprender cómo una vida en los márgenes de la legalidad se empieza a parecer a una vida legítima, donde sujetos sin reconocimiento social participan como ciudadanos al mismo tiempo - y a través de los mismos documentos - que se institucionaliza su exclusión. Y acá pasamos de una reflexión metodológica a la epistemología de la experiencia cotidiana, pues los usos y prácticas asociadas a los papeles implican entender el conocimiento fraccionado como tal, y en vez de poner sobre la mesa los mecanismos objetivos que ignora, requiere que no entendamos el todo para poder entender a los jornaleros.

La ciudadanía paralela que he descrito se inscribe dentro de la sociedad estadounidense de una forma implícitamente violenta. Mientras que muchas personas, tanto los críticos como los defensores de estas poblaciones, podrían argumentar que los inmigrantes llevan una vida bastante tranquila, basta con ver cómo estas prácticas de documentación crean situaciones donde la única respuesta es esconderse y reforzar la marginalidad.. De esta forma, en las interacciones donde se presentan los documentos siempre hay un riesgo, y éste es una función del ambiente político local. Si la migra hace redadas en localidades cercanas, nadie se atreve a salir por unos días; los servicios de transporte, de la ciudad, y cualquier interacción donde 
pueda verse uno obligado a mostrar "papeles", son evitados. Y en algunos casos cuando la represión migratoria o policial se "siente" incrementar, hombres que han tenido encuentros pasajeros con autoridades locales u ONGs donde han mostrado sus documentos, se mudan repentinamente, cambiando así su dirección y en ocasiones dejando vencer sus teléfonos celulares para luego comprar otros con números distintos.

Así, para entender cómo se constituye una población que está realmente atrapada entre la marginalización social y la inclusión parcial, es necesario buscar las prácticas a través de las cuales se hace posible una cotidianidad manejable. Estas prácticas no son espectaculares; no hay acción o reacción política a las contingencias migratorias desde la población misma. Mas bien lo que se encuentra es el uso confuso de documentos de diferentes índoles en situaciones complejas que conllevan a desenlaces inciertos pero que en general hacen posible un día a día repetible y reconocible. Al fin y al cabo, aunque consideran su situación como una que es precaria en todos los sentidos, la mayoría de los jornaleros pasan las semanas preocupados por problemas que no están directamente relacionados con su situación irregular, sino que tienen que ver con conseguir suficiente dinero para sostenerse y mandar remesas a su familia. La ciudadanía paralela permite una ficción de cotidianidad inscrita en un mundo social particular de tal forma que los jornaleros actúan y se desenvuelven como miembros productivos de su entorno. Se tolera y en ocasiones promueve el uso de documentos informales para poder "leer" y "actuar" sobre la población al mismo tiempo que se asegura que sea imposible su reconocimiento legal. Esto a través del carácter doble de los documentos que sí se pueden obtener y usar y que son, a la vez, reconocibles al estado y a la sociedad, pero inaceptables de cara a sus estructuras de legitimación social. Tal vez sea en esta dualidad imposible que algunos documentos adquieren poder y casi consciencia propia y se convierten, en si mismos, en generadores de legitimidad, eso sí, si uno tiene suerte.

\section{Referencias Bibliográficas}

AGAMBEN, Giorgio

1998 Homo Sacer: Sovereign Power and Bare Life. Stanford: Stanford University Press.

APPADURAI, Arjun

1996 Modernity at Large: Cultural Dimensions of Globalization. Minneapolis: University of Minnesota Press.

ARENDT, Hannah

1979 The Origins of Totalitarianism. San Diego: Harcourt Inc.

CHAVEZ, Leo R.

2001 Covering Immigration: Popular Images and the Politics of the Nation. Berkeley: University of California Press.

COUTIN, Susan Bibler

1993 The Culture of Protest: Religious Activism and the U.S. Sanctuary Movement. Boulder: Westview Press. 
2000 Legalizing moves: Salvadoran Immigrants'Struggle for U.S. Residency. Ann Arbor: University of Michigan Press.

2005 "Being en Route". American Anthropologist 107:195-206.

DAS, Veena

2004 "The Signature of the State: the Paradox of Illegibility". En Anthropology in the Margins of the State. V. Das and D. Poole, eds. Pp. 225-252. Santa Fe: N.M

DE GENOVA, Nicholas

2002 “Migrant 'Illegality' and Deportability in Everyday Life”. Annual Review of Anthropology 31(1):419-447.

FERGUSON, James

1999 Expectations of Modernity: Myths and Meanings of Urban Life on the Zambian Copperbelt. Berkeley: University of California Press.

HOLSTON, James

1999 "Spaces of Insurgent Citizenship". En Cities and Citizenship. J. Holston ed. Pp. 155-173 Durham [N.C.]: Duke University Press.

2008 Insurgent Citizenship: Disjunctions of Democracy and Modernity in Brazil. Princeton: Princeton University Press.

HOLSTON, James; APPADURAI, Arjun.

1999 "Introduction: Cities and Citizenship". Pp. 1-18 en J. Holston (ed.) Cities and Citizenship. Durham: Duke University Press.

INDA, Jonathan Xavier.

2006 Targeting Immigrants: Government, Technology, and Ethics. Oxford: Blackwell Pub.

LOESCHER, Gil.

1993 Beyond Charity: International Cooperation and the Global Refugee Crisis. New York: Oxford University Press.

MALPICA, Daniel Melero.

2002 "Making a Living in the Streets of Los Angeles: An Ethnographic Study of Day Laborers". Migraciones Internacionales 1:124-148.

NGAI, Mae M.

2004 Impossible Subjects: Illegal Aliens and the Making of Modern America. Princeton: Princeton University Press.

ONG, Aihwa

1999 Flexible Citizenship: the Cultural Logics of Transnationality. Durham: Duke University Press.

2003 Buddha is Hiding: Refugees, Citizenship, the New America. Berkeley: University of California Press.

2006 Neoliberalism as Exception: Mutations in Citizenship and Sovereignty. Durham: Duke University Press. 
ORDONEZ, Juan Thomas

2008 "The State of Confusion: Reflections on Central American Asylum Seekers in the Bay Area". Ethnography 9:35-60.

2012 “Boots for my Sancho': Structural Vulnerability Among Latin American Day Labourers in Berkeley, California”. Culture, Health \& Sexuality 14(6): 691-703

PINEDO TURNOVSKY, Carolyn.

2006 “A la Parada: The Social Practices of Men on a Street Corner". Social Text 88, 24 (3):55-72.

PURSER, Gretchen.

2009 "The Dignity of Job-Seeking Men: Boundary Work Among Immigrant Day Laborers". Journal of Contemporary Ethnography 38:117-139.

QUESADA, James; HART, Laurie; BOURGOIS, Philippe

2011 "Structural Vulnerability and Health: Latino Migrant Laborers in the United States". Medical Anthropology 30:339-362.

SAHLINS, Peter

1989 Boundaries: the Making of France and Spain in the Pyrenees. Berkeley: University of California Press.

SASSEN, Saskia

2006 Territory, Authority, Rights: From Medieval to Global Assemblages. Princeton: Princeton University Press.

2008 Los Espectros de la Globalización. México: Fondo de Cultura Económica.

SCOTT, James C.

1998 Seeing Like a State: How Certain Schemes to Improve the Human Condition have Failed. New Haven: Yale University Press.

STEPHEN, Lynn

2007 Transborder Lives: Indigenous Oaxacans in Mexico, California, and Oregon. Durham: Duke University Press.

SUÁREZ NAVAZ, Liliana

1999 “La construccion social del 'Fetichismo de los Papeles': Ley e identidad en la frontera sur de Europa”. Actas del VIII Congreso de Antropología Social, IV. Simposio de Antropología Jurídica. Santiago de Compostela. 